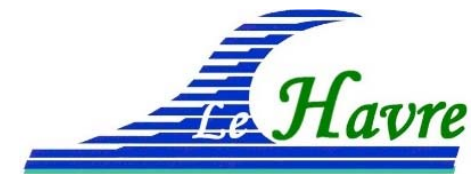

XVI èmes Journées Nationales Génie Côtier - Génie Civil

Le Havre, 2020

DOI:10.5150/jngcgc.2020.059 (C) Editions Paralia CFL

disponible en ligne - http://www.paralia.fr - available online

\title{
Influence of the aspect ratio on the behaviour of an undulating membrane tidal energy converter
}

\author{
Martin MOREAU ${ }^{1,2}$, Martin TRÄSCH ${ }^{2}$, \\ Sylvain DELACROIX ${ }^{2}$, Grégory GERMAIN ${ }^{1}$
}

1. IFREMER, Marine Structure Laboratory, 150 Quai Gambetta, 62200 Boulogne-surMer, France. gregory.germain@ifremer.fr

2. EEL Energy SAS, 98 Quai Gambetta, 62200 Boulogne-sur-Mer, France. contact@eel-energy.fr

\begin{abstract}
An experimental study of a $1 / 20^{\text {th }}$ scale undulating membrane tidal energy converter (UMTEC) based on EEL Energy's device is presented to assess the impact of the membrane's aspect ratio on its behaviour. The aim of this work is to study 3D effects on the machine to optimise the energy extraction. Five aspect ratios from 0.26 to 0.57 are tested at constant length, keeping other geometric parameters constant too. The mechanical energy of the membrane is conveyed above the free surface by a vertical cogwheel/chain assembly to be converted by an electric generator.

After describing the experimental set-up, results are presented according to the reduced flow speed. Undulation dynamics and power conversion are analysed. This study highlights the effects of an undulation mode change on the undulation amplitude and frequency, independently from the aspect ratio. In addition, it shows that the UMTEC performances increase with the aspect ratio up to 0.5 . Over this aspect ratio value, the efficiency of the device seems to stagnate at its highest value, suggesting that $3 \mathrm{D}$ effects become negligible.
\end{abstract}

\section{Keywords}

Tidal energy converter, Fluid-Structure interaction, Aspect ratio, Flume tank experiments.

\section{Introduction}

Various tidal energy converter (TEC) concepts are being developed as reviewed by (DAY et al., 2015). While most of these technologies are inspired by turbines and benefit from the industrial knowledge acquired on it, EEL Energy's concept is based on an undulating membrane under a fluid-structure interaction (DEPORTE, 2016). This system uses the interaction between a pre-stressed semi-rigid plate and an axial flow to generate undulations that are converted into electrical power. The dynamic behaviour and a power 


\section{Thème 5 - Énergies et ressources marines}

estimates of this device were assessed by experimental studies on a $1 / 20^{\text {th }}$ scale prototype (TRASCH et al., 2018). Besides, a 2D linear analytical model of the undulating tidal energy converter was developed (TRASCH et al., 2019). An experimental study on the membrane's geometry was needed to quantify $3 \mathrm{D}$ effects.

In order to study the effects of the width-to-length ratio on the membrane's behaviour, a specific experimental campaign has been carried out. The influence of this parameter, called aspect ratio, has been massively studied for fluttering flags and plates as reviewed in (PAIDOUSSIS, 2003). Most of these studies aim to define physical models to predict the critical velocity for the onset of flutter. (ARGENTINA \& MAHADEVAN, 2005; ELOY et al., 2007) show that the smaller the span, the higher the critical velocity over which the plate undulates, and so the more stable the system. Only few papers deal with the overall dynamic response of finite dimension plates to flutter instability. (BAO et al., 2010) experiment a slight variation of reduced frequency with aspect ratio for finite-span flexible plates. They also show an increase of the reduced velocity needed to enter a higher flutter mode when the aspect ratio is small. Finally, (VIROT et al., 2013) point out a discontinuity of unsteady fluid forces and a reduction of flapping amplitude before the onset of another flutter regime that reflects a change of undulation envelope. Nevertheless, fluttering flags or plates are quite different from the case studied here as the undulating membrane presented below is pre-stressed and equipped with a power take-off system.

In this paper, a $1 / 20^{\text {th }}$ scale prototype of the UMTEC is tested in a flume tank. The experimental set-up is described first and similarity parameters are defined to extrapolate the results. Then, the results in terms of membrane's dynamics and efficiency are exposed to discuss the impact of aspect ratio on the machine operation.

\section{Experimental methods}

Tests are carried out in the Ifremer wave and current circulating flume tank with a $L_{b} \times W_{b} \times H_{b}=(18 \mathrm{~m}) \times(4 \mathrm{~m}) \times(2 \mathrm{~m})$ test section. The flow presents a mean turbulent intensity of $1.5 \%$ (GAURIER et al., 2019) and Reynolds number with the membrane's length as characteristic dimension varies between $0.7 \times 10^{6}$ and $2.0 \times 10^{6}$.

The $1 / 20^{\text {th }}$ scale prototype of an undulating membrane tidal energy converter used in this study is made of a polyacetal POM C plate (TRASCH et al., 2017) of original dimensions $L \times W \times H=(1.3 \mathrm{~m}) \times(0.735 \mathrm{~m}) \times(0.003 \mathrm{~m})$ (figure $1 \mathrm{a})$. To ensure a two-dimensional displacement, the membrane is stiffened by transverse carbon/epoxy bars at its leading and trailing edges. The structure is pre-stressed by cables fixed between the two stiffeners. They are shorter than the membrane's length to bend it initially. A $0.88 \times L$ length was chosen empirically to stabilise the undulation and increase its amplitude. The energy extracted from the flow through the undulation of the structure is transmitted to a mast fixed on a third stiffener placed on the downstream part of the membrane. At its top, the mast is fixed to the lower part of a cart that translates along a tubular structure (figure 1c). 


\section{XVİ̀mes Journées Nationales Génie Côtier - Génie Civil \\ Le Havre 2020}

The upper part of the cart is linked to a chain that rotates the generator's axis via cogs ensuring an appropriate rotational speed of the generator. The latter is electronically driven by current pulse-width modulation which controls its force-to-velocity linear coefficient, called damping coefficient $\left(C_{a m}\right)$.

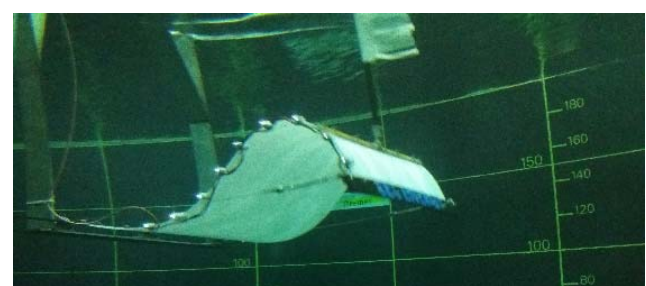

(a) $1 / 20^{\text {th }}$ scale prototype under water.

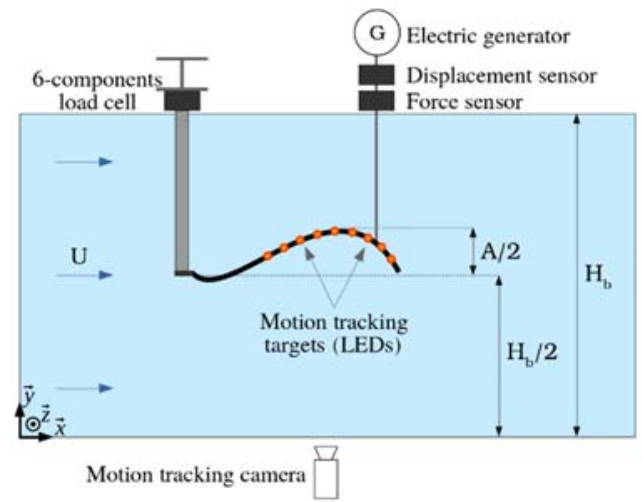

(b) Instrumentation scheme.

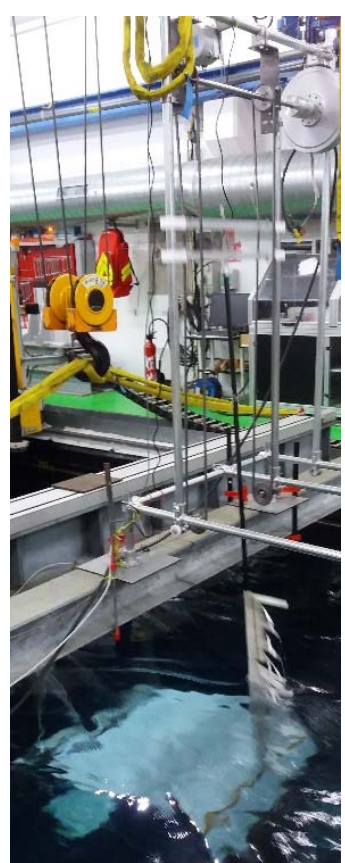

(c) Energy conversion system.

Figure 1. Presentation of the $1 / 20^{\text {th }}$ scale UMTEC and its instrumentation.

The membrane's geometry is characterised by its aspect ratio defined as:

$$
A R=\frac{W}{L}
$$

For this study, five aspect ratios are tested from $A R=0.57$ to 0.26 . A membrane of length $L=1.3 \mathrm{~m}$ is shortened in its width by $10 \mathrm{~cm}$ between each case except for $A R=0.49$ which will be represented by a membrane a bit longer, $1.4 \mathrm{~m}$, that is of the same surface as the $A R=0.57$ membrane. The membranes are tested at damping coefficient divided by their width $\left(C_{a m} / W\right)$ constant to underline 3D effects. $C_{a m} / W$ from 200 to $700 \mathrm{~kg} / \mathrm{s} / \mathrm{m}$ by steps of 100 are tested for each membrane.

Instrumentation for these tests is composed of a 6-components load cell attached to the prototype's frame to measure the lift and drag forces (figure 1b). In addition, an S-shape force sensor is placed between the two parts of the cart and a draw-wire displacement sensor follows the mast. Thus, the mechanical power extracted $\left(P_{\text {mech }}\right)$ is computed as the product between the force and the time derivative of the displacement measured on the mast. The acquisition frequency $\left(f_{a c q}\right)$ of these sensors is $2000 \mathrm{~Hz}$. Finally, a motion tracking system composed of a camera $\left(1024 \mathrm{px} \times 1296 \mathrm{px}, f_{a c q}=100 \mathrm{~Hz}\right)$ and 9 LEDs as targets records the membrane's global displacements. 


\section{Thème 5 - Énergies et ressources marines}

To be relevant at other scales, the data must be non-dimensionalised. To this aim, the reduced velocity is defined (ELOY et al., 2007):

$$
U_{r}=U L \sqrt{\frac{12 \rho_{s}}{E H^{2}}}
$$

It considers both the upstream flow speed $(U)$ and the membrane's stiffness which are major parameters governing the structure's behaviour (TRASCH, 2019). Besides, it will be interesting to analyse reduced amplitudes and frequencies, respectively $A^{*}=A / L$ and $f^{*}=f L / U$. Finally, a power coefficient $\left(C p_{L}\right)$ is defined to assess the power extracted compared to the hydrodynamic power theoretically available. $C p_{L}$ values being confidential, it is presented divided by the highest value plotted and noted $C p_{L}^{*}$.

$$
C p_{L}=\frac{P_{\text {mec } h}}{0.5 \rho_{f} L W U^{3}} \quad ; \quad C p_{L}^{*}=\frac{C p_{L}}{C p_{L_{\max }}}
$$

\section{Effects of the aspect ratio}

To present the results synthetically, only cases at damping $C_{a m} / W=500 \mathrm{~kg} / \mathrm{s} / \mathrm{m}$ will be presented. It is the overall optimal value on the velocity range considered and is also representative of behaviours at other damping values. In the following, dynamics of the membrane is studied first to assess the impact of the aspect ratio on the membranes motion. Then, the efficiency of the UMTEC is analysed versus the aspect ratio.

\subsection{Undulating membrane dynamics}

The evolution of reduced frequency presented in figure 2 seems independent from the aspect ratio, increasing monotonically with the reduced velocity and tending to an asymptotic value. However, at fixed $U_{r}$, the reduced frequency is significantly lower for $A R=0.26$ and gets higher with the aspect ratio up to 0.49 before a slight decrease at 0.57 . In addition, it is interesting to notice that, around $U_{r}=1.3$, a sensible change of curve slope appears. Indeed, $f^{*}$ follows a slope of approximately 0.45 with $U_{r}$ from 1 to 1.3 while it is less sloping after, about 0.11 .

Besides, the reduced amplitude at the mast's position, plotted in figure 2, is averaged over periods during the whole acquisition time. Depending on the undulation frequency, this average is computed over 5 to 27 periods. From $U_{r}=1$ to 1.3 , reduced amplitudes decrease, independently from the aspect ratio. At $U_{r} \approx 1.3$, for $A R>0.26$, membranes show a local minimum of reduced amplitude at $A^{*} \approx 0.5$. Then, for $U_{r}>1.3$, the reduced amplitude increases up to a local maximum at $U_{r}=1.62$ and decreases again.

Reduced amplitude and frequency both show a significant change of evolution around $U_{r}$ $=1.3$. To explain this phenomenon, the figure 3 displays the motion tracking of the 0.57 aspect ratio membrane. Three different reduced velocities around that value $\left(U_{r} \in\{1.04\right.$; $1.27 ; 1.62\})$ are represented. Positions $(X ; Y)$ are non-dimensionalised by the membrane's length at rest $L$. Thus, the trailing edge's maximum horizontal position is at $0.88 \times L$ and 


\section{XVİ̀mes Journées Nationales Génie Côtier - Génie Civil \\ Le Havre 2020}

the last target's one at $0.8 \times L$ due to the withdraw cables that pre-stress the membrane. Blue curves draw the targets displacement during the whole acquisition time and black ones join targets positions at given moments to display the membrane's curvature. It is chosen to display results for $A R=0.57$ as they are the cleanest (targets were lost more often by the tracking system for the other aspect ratios) and representative of the behaviours observed for the other aspect ratios down to $A R=0.33$.
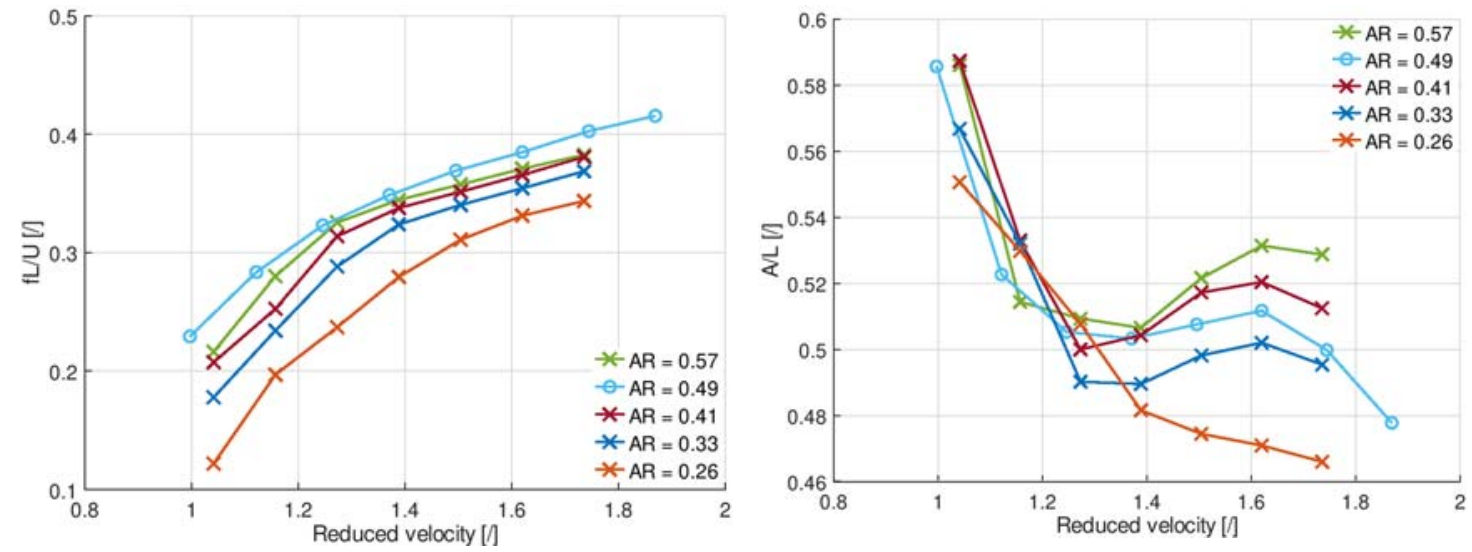

Figure 2. Reduced frequency (left) and amplitude (right) versus reduced velocity for the five aspect ratios at $C_{a m} W=500 \mathrm{~kg} / \mathrm{s} / \mathrm{m}$.

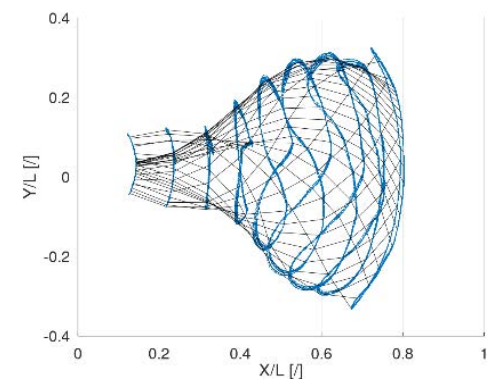

(a) $U_{r}=1.04$

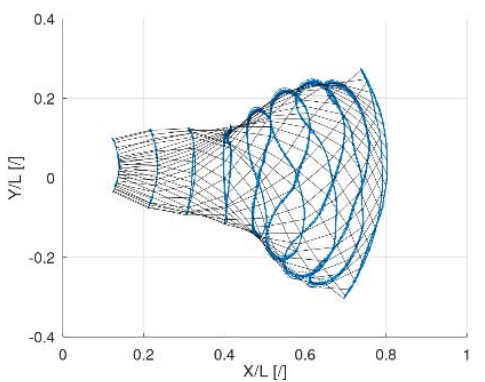

(b) $U_{r}=1.27$

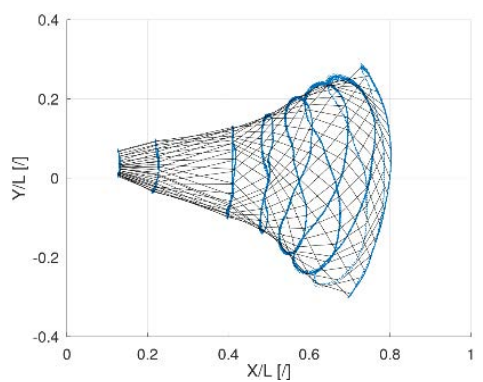

(c) $U_{r}=1.62$

Figure 3. Displacement along time of the 0.57 aspect ratio membrane at three different reduced velocities. Blue curves represent the position of targets at each time and black lines the global curvature of the membrane at given times.

The region where the membrane undulates is called the undulation envelope. Ahead of the singular reduced velocity $\left(U_{r} \approx 1.3\right.$ ), this envelope presents a neck before which it is rather thin and after which it becomes rounded. The neck is strongly marked at $X / L \approx 0.35$ for $U_{r}=1.04$ (figure 3a). As the reduced velocity increases, the neck progressively moves back on the membrane's length and becomes less pronounced (figure 3.b). Finally, after the singular reduced velocity, the neck vanishes and the envelope almost looks like a cone cross-section (figure $3 \mathrm{c}$ ). Thus, for $A R \geq 0.33$, the minimum of reduced amplitude and the change of slope of the reduced frequency reflects a change of envelope due to an evolution 


\section{Thème 5 - Énergies et ressources marines}

of the undulation mode. It is interesting to notice that (VIROT et al., 2013) also identified a reduction of flapping amplitude before the on-set of another flutter mode for flags as described here on figures 2 and 3.

The behaviour of $A R=0.26$ looks different from others with no $A^{*}$ minimum in the reduced velocity range tested and a much lower amplitude at high reduced velocities. (BAO et al., 2010) shows for flags that the critical velocity for the on-set of another flutter regime is rather independent of the aspect ratio over a certain value and then increase significantly when the aspect ratio decreases below. So, assuming a similar dependence to the aspect ratio for EEL Energy's membrane with a limit around 0.3, it would be consistent with Bao's observation to see a rather constant transition velocity for $A R \geq 0.33$ and to have it shifted to a higher reduced velocity for $A R=0.26$.

\subsection{Power conversion}

Figure 4 displays the power coefficient, $C p_{L}{ }^{*}$, that represents the ratio between the mechanical power extracted from the flow and the theoretical power available (eq. 3). For each aspect ratio, $C p_{L}{ }^{*}$ first rises with the reduced velocity before stagnating around its highest value and then decay a little. The onset of this stagnancy occurs at a constant reduced velocity for $A R \geq 0.41$. For lower aspect ratios, however, a higher reduced velocity is needed to reach values close to the maximum, narrowing the range of high efficiency.

In addition, the power coefficient is plotted versus the aspect ratio on the right of the figure 4 to give another point of view on their dependency. It appears clearly that, no matter the reduced velocity, the performances of the undulating membrane tidal energy converter decrease with the aspect ratio. Indeed, at a given reduced velocity, the power coefficient is 30 to $35 \%$ lower for the 0.26 aspect ratio membrane than for the 0.57 one. Furthermore, not only $C p_{L}{ }^{*}$ decreases but the rate of this decline increases when the aspect ratio decreases.

ARGENTINA and MAHADEVAN (2005) address the importance of 3D-effects, noted $I$, on fluid-flow-induced fluttering flags using a numerical model. They define a relation between $I$ and $A R$ through two asymptotic behaviours. First, they consider that when the aspect ratio tends to zero, a variation of aspect ratio induces a variation of the importance of $3 \mathrm{D}$-effects in the same order of magnitude $(I / A R \rightarrow 1$ when $A R \rightarrow 0)$. Consequently, the performance reduction observed for low aspect ratios is likely due to some phenomena taking place in the crossflow direction, such as flow curling around the membrane's sides. Secondly, they show that for infinite width (i.e. infinite aspect ratio), the importance of the third dimension is negligible. Thus, in the light of their study and previous tests, it seems that, over 0.5 , the aspect ratio does not affect the power coefficient significantly. The latter keeps growing slightly with $A R$, tending to its asymptotic value $C p_{L}{ }^{*}$ max.

To sum up, an undulating membrane tidal energy converter with a high aspect ratio can supply a higher efficiency on a larger reduced velocity range. 


\section{XVİ̀mes Journées Nationales Génie Côtier - Génie Civil \\ Le Havre 2020}
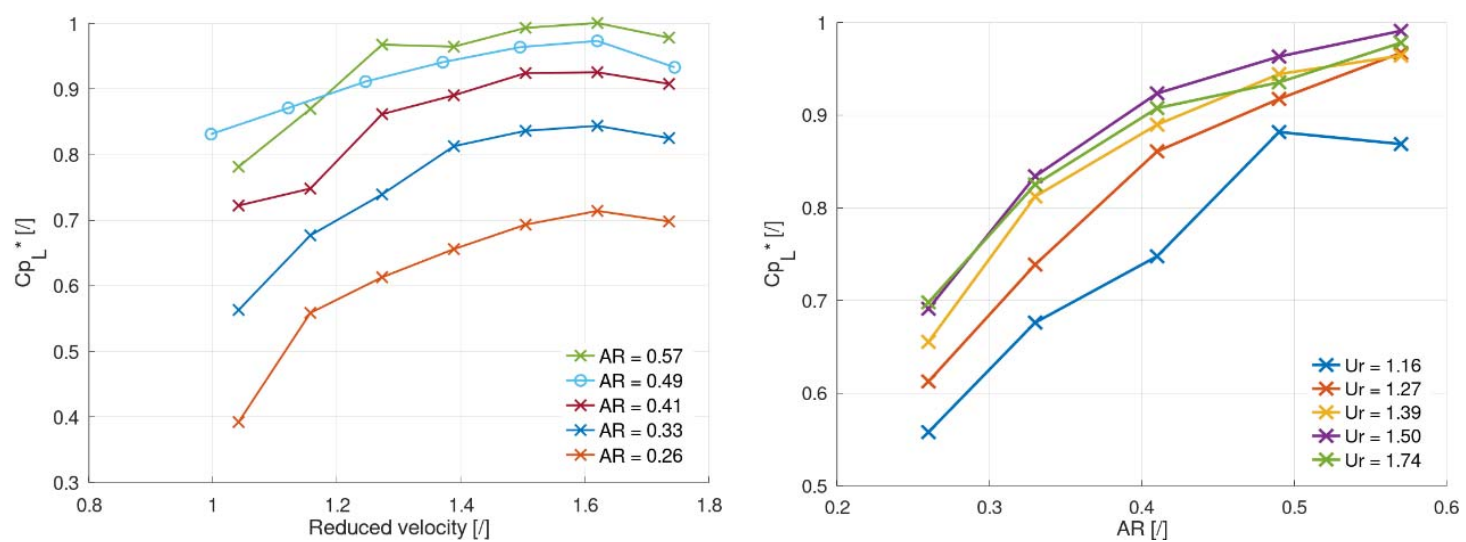

Figure 4. Power coefficient divided by its highest value versus reduced velocity (left) and versus aspect ratio (right) at Cam $/ W=500 \mathrm{~kg} / \mathrm{s} / \mathrm{m}$.

\section{Conclusion and perspectives}

Experiments have been carried out in the Ifremer flume tank in Boulogne-sur-Mer to characterise the impact of aspect ratio on the behaviour of an undulating membrane tidal energy converter. Membranes 1.75 to 3.85 times longer than wide $(0.57>A R>0.26)$ were tested at flow velocities between 0.8 and $1.5 \mathrm{~m} / \mathrm{s}$. It was shown that, at a reduced velocity close to 1.3 and for membranes of aspect ratio higher than 0.33 , reduced amplitudes admit a minimum and reduced frequencies show a significant change of slope. The motion tracking analysis revealed that this reflects a change of the undulation mode. The fact that this change occurs at the same reduced velocity for all the aspect ratios also shows the relevance of this similarity parameter for EEL Energy's device.

Furthermore, it appeared that for aspect ratios below 0.5 , meaning for $L>2 W$, phenomena happening in the crossflow direction makes the machine's performances decay significantly. This loss seems to become even more important when the aspect ratio reaches small values. On the opposite, for aspect ratios over 0.5 , previous experiments and other studies suggest that the undulating membranes efficiency stagnates at its highest value, independently from the aspect ratio. Thus, for the design of higher scale machines, membranes of aspect ratios over 0.5 should be used to minimise $3 \mathrm{D}$ effects and maximise the power extraction. The non-dimensional parameters defined in this paper will be useful tools to scale up the device, in terms of geometry and mechanical properties. However, the sites' specificities (velocity range, turbulence, free surface elevation...) will also have to be considered to succeed.

\section{Acknowledgment}

The authors acknowledge EEL Energy and Bpifrance for their support in this study. This work was also partly financially supported by the European Union (FEDER), the French government, IFREMER and the region Hauts-de-France in the framework of the project CPER 2015-2020 MARCO. 


\section{Thème 5 - Énergies et ressources marines}

\section{References}

ARGENTINA M., MAHADEVAN L. (2005). Fluid-Flow-induced flutter of a flag. Proc. of the National Academy of Sciences, Vol. 102(6), pp 1829-1834. https://doi.org/10.1073/pnas.0408383102

BAO C.-Y., TANG C., YIN X.-Z., LU X.-Y. (2010). Flutter of finite-span flexible plates in uniform flow. Chinese Physics Letters, Vol. 27(6). https://doi.org/10.1088/0256-307X/27/6/064601 DAY A., BABARIT A., FONTAINE A., HE Y.-P., KRASKOWSKI M., MURAI, M. (2015). Hydrodynamic modelling of marine renewable energy devices: A state of the art review. Ocean Engineering, Vol. 108, pp 46-69. https://doi.org/10.1016/j.oceaneng.2015.05.036 DEPORTE A. (2016). Caractérisation du fonctionnement d'une hydrolienne à membrane ondulante pour la récupération de l'énergie des courants marins. $\mathrm{PhD}$ thesis, Université de Bretagne occidentale, 238 p. https://archimer.ifremer.fr/doc/00349/46002/

ELOY C., SOUILLIEZ C., SCHOUVEILER L. (2007). Flutter of a rectangular plate. Journal of Fluids and Structures, Vol. 23(6), pp 904-919. https://doi.org/10.1016/i.jfluidstructs.2007.02.002

GAURIER B., GERMAIN G., PINON G. (2019). How to correctly measure turbulent upstream flow for marine current turbine performances evaluation? In Advances in Renewable Energies Offshore, Proceedings of the $3^{\text {rd }}$ International Conference on Renewable Energies Offshore (RENEW 2018), October 8-10, 2018, Lisbon, Portugal. 1st Edition, Carlos Guedes Soares (Ed.), pp 23-30. https://archimer.ifremer.fr/doc/00461/57308/

PAIDOUSSIS M. (2003). Plates in axial flow. In Slender Structures and Axial Flow, volume 2 of Fluid-Structure Interactions, pp 1137-1220. Academic Press.

TRASCH M., DEPORTE A., DELACROIX S., DREVET J.-B., GAURIER B., GERMAIN G. (2018). Power estimates of an undulating membrane tidal energy converter. Ocean Engineering, Vol. 148, pp 115-124. https://doi.org/10.1016/j.oceaneng.2017.11.002 TRASCH M., DEPORTE A., DREVET J.-B., GERMAIN G. (2017). Impact of cables withdraw length on the dynamics of an undulating membrane tidal energy converter. In Proceedings of the $12^{\text {th }}$ European Wave and Tidal Energy Conference, EWTEC, 2017. TRASCH M., DEPORTE A., DELACROIX S., GERMAIN G., DREVET J.-B. (2019). Analytical linear modelization of a buckled undulating membrane tidal energy converter. Renewable Energy, Vol. 130, pp 245-255. https://doi.org/10.1016/j.renene.2018.06.049 VIROT E., AMANDOLESE X., HEMON P. (2013). Fluttering flags: An experimental study of fluid forces. Journal of Fluids and Structures, Vol. 43, pp 385-401. https://doi.org/10.1016/j.jfluidstructs.2013.09.012 